\title{
Article
}

\section{Classificatory multiplicity: intimate partner violence diagnosis in emergency department consultations}

Olive, Philippa

Available at http://clok.uclan.ac.uk/17122/

Olive, Philippa ORCID: 0000-0002-9175-1285 (2017) Classificatory multiplicity: intimate partner violence diagnosis in emergency department consultations. Journal of Clinical Nursing, 26 (15-16). pp. 2229-2243. ISSN 0962-1067

It is advisable to refer to the publisher's version if you intend to cite from the work. http://dx.doi.org/10.1111/jocn.13673

For more information about UCLan's research in this area go to http://www.uclan.ac.uk/researchgroups/ and search for < name of research Group>.

For information about Research generally at UCLan please go to http://www.uclan.ac.uk/research/

All outputs in CLoK are protected by Intellectual Property Rights law, including Copyright law. Copyright, IPR and Moral Rights for the works on this site are retained by the individual authors and/or other copyright owners. Terms and conditions for use of this material are defined in the policies page.

\section{CLoK}

Central Lancashire online Knowledge www.clok.uclan.ac.uk

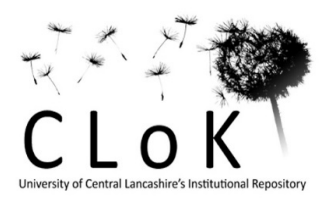




\section{TITLE PAGE}

FULL TITLE: Classificatory multiplicity: intimate partner violence diagnosis in emergency department consultations

CONCISE TITLE: Intimate partner violence diagnosis

AUTHOR: $\quad$ Dr. Philippa Olive, PhD Sociology; MSc Research and Development; BSc Nursing; PgCE TLHE; RGN; RSCN.

Senior Research Fellow in Health Services Research

College of Health and Wellbeing

University of Central Lancashire

Preston

PR1 2HE

United Kingdom

POlive1@uclan.ac.uk

@philippaolive

FUNDING: This research was funded by a National Institute for Health Research Doctoral Research Fellowship (NIHR DRF). This article presents independent research funded by the National Institute for Health Research (NIHR). The views expressed are those of the author(s) and not necessarily those of the NHS, the NIHR or the Department of Health.

Conflict of interest: None declared

Acknowledgements: With many thanks to all participants and organisations for their interest and participation and without whom this research would not have been possible. Thanks also to JCN's editorial board and anonymous reviewers for their constructive comments which undoubtedly strengthened the manuscript.

This is the peer reviewed version of the following article: Olive, P. (2017) Classificatory Multiplicity: intimate partner violence diagnosis in emergency department consultations, Journal of Clinical Nursing. DOI:10.1111/jocn.13673, which has been published in final form at [http://onlinelibrary.wiley.com/doi/10.1111/jocn.13673/full]. This article may be used for non-commercial purposes in accordance with Wiley Terms and Conditions for Self-Archiving. 
ABSTRACT

\section{Aims and Objectives}

The aim of this research was to explore the naming, or classification, of physical assaults by a partner as 'intimate partner violence' during emergency department consultations.

\section{Background}

Research continues to evidence instances when intimate partner physical violence is 'missed' or unacknowledged during emergency department consultations.

\section{Methods}

Theoretically this research was approached through complexity theory and the sociology of diagnosis. Research design was an applied, descriptive and explanatory, multiple-method approach that combined: qualitative semi-structured interviews with service users $(n=8)$ and emergency department practitioners $(n=9)$, and qualitative and quantitative document analysis of emergency department health records $(n=28)$.

\section{Results}

This study found that multiple classifications of intimate partner violence were mobilised during emergency department consultations and that these different versions of intimate partner violence held different diagnostic categories, processes, and consequences.

\section{Conclusion}

The construction of different versions of intimate partner violence in emergency department consultations could explain variance in people's experiences and outcomes of consultations. The research found that the classificatory threshold for 'intimate partner violence' was too high. Strengthening systems of diagnosis (identification and intervention) so that all incidents of partner violence are named as 'intimate partner violence' will reduce the incidence of missed cases and afford earlier specialist intervention to reduce violence and limit its harms.

\section{Relevance to Clinical Practice}

This research found that identification of and response to intimate partner violence, even in contexts of severe physical violence, was contingent. By lowering the classificatory threshold so that all incidents of partner violence are named as 'intimate partner violence', practitioners could make a significant contribution to reducing missed intimate partner violence during consultations and improving health outcomes for this population. This research has relevance for practitioners in any setting where service-user report of intimate partner violence is possible. 


\section{SUMMARY BOX}

What does this paper contribute to wider global community?

- Identification of and response to intimate partner violence, even in contexts of severe physical violence was found to be contingent.

- Classification of intimate partner violence was connected to: legal duty to respond statutory frameworks of risk of harms; socio-cultural discourses about what counts as intimate partner violence; and health care practitioners' perceptions of usual modes of disclosure.

- Connecting all reports of partner perpetrated violence to intimate partner violence identification and intervention will reduce missed cases in health consultations and mobilise earlier intervention to reduce violence and limit its harms.

- The sociology of diagnosis is a valuable conceptual tool for examining variance in identification and response for a wide range of determinants of health of concern for nurses and allied professions.

\section{KEYWORDS}

Intimate Partner Violence; Domestic Violence; Violence Against Women; Accident and Emergency; Emergency Care; Emergency Department; Health Service Research; Diagnosis; Classification; Sociology. 


\section{INTRODUCTION}

Despite its massive health consequences (WHO 2013a, Black et al 2011) health services have been slow to address intimate partner violence during health consultations (WHO 2013a, Taft et al 2013). Research has evidenced that identification and response to intimate partner violence has failed to become effectively embedded in practice (Howard et al 2010, WNC 2010, BCCEWH 2013). There is a renewed imperative globally for health services to identify and respond to intimate partner violence (WHO 2013b, NICE 2014) and current policy goals aim for early identification and intervention (WHO 2013b, NICE 2014) to reduce incidents of intimate partner violence and limit its harms.

\section{BACKGROUND}

At least one percent of emergency department patients attend because of injuries sustained from intimate partner physical violence (Olive 2007). Yet some service users attending emergency departments following high severity acts of partner violence and incurring significant injury, report that only their physical injury and not their experience of intimate partner violence was attended to during the consultation (WNC 2010, BCCEWH 2013).

Identification of intimate partner violence in health consultations is important so that people's experiences are validated and specialist intervention can be mobilised. Much work has been undertaken to make health environments more conducive to identification (Hathaway et al 2002, Coben 2002), by increasing practitioners' skills of enquiry (Feder et al 2009, Boursnell and Prosser 2010, Beynon et al 2012), and formally embedding identification into practice documentation (Choo et al 2012). However, we also know that reasoning behind serviceuser decisions of whether to report intimate partner violence during emergency department consultations, even if asked, are complex. Factors likely to impact whether women report intimate partner violence or not have been identified as dependent on: the severity of violence (Walby and Allen 2004), fear for life (Catallo et al 2013), concern for children (Coy and Kelly 2011, WNC 2010, Catallo et al 2013), perceptions of what counts as intimate 
partner violence (Walby and Allen 2004), needing medical care (Catallo et al 2013), accessibility of services (WNC 2010, Coy and Kelly 2010), and risk-benefit analysis of the intrusion in life that report may bring (Catallo et al 2013).

To date research about identification of intimate partner violence during emergency department consultations has focused on exploring reasons behind practitioners' nonenquiry and/or service-users non-disclosure. Taking a unique approach, the aim of this research was to explore the naming, or classification, of physical assaults by a partner as 'intimate partner violence' during emergency department consultations to explain why it may sometimes be unrecognised or missed.

\section{Theoretical framework}

This research was approached through a synthesis of complexity theory (Walby 2003, Cilliers 1998) and the sociology of diagnosis (Brown 1995; Jutel 2011). Complexity theory originates from systems theory (Ramage and Shipp 2009) and explains our experienced realities as products of myriad intersecting systems. In complexity theory all things (including people) are systems and all systems have all other systems as their environment (Walby 2003). This means that there are unceasing multi-directional interactions between systems which continually shape our experiences and therefore any causal explanations of phenomena are likely to be complex, multi-directional and partial. Jutel's (2011) sociology of diagnosis conceptualises a 'diagnosis' as a product of its category or definitional boundary, the processes by which it can become identified, and the consequences, or interventions, attached to its identification. This means that diagnoses are not fixed; their thresholds can shift as categories, processes, or consequences alter in response to new knowledge and practices. Through this theoretical framing dynamic, multiple and intersecting properties of systems that lie behind patterns and experiences of intimate partner violence identification during health consultations can be credibly described. 
Diagnosis and upstream social determinants of health

Health policy (WHO 2013b, NICE 2014) more commonly uses terms such as: 'identifying' and 'responding' rather than diagnosis when referring to service provision for intimate partner violence which likely reflects its social, non-biomedical origins. Still, in health, and indeed other industries, to diagnose a problem means to identify a phenomenon's nature and cause. By approaching this research through the sociology of diagnosis the intention was not to pathologise intimate partner violence but rather to propose that the sociology of diagnosis offers a helpful conceptual tool for examining the identification of upstream social determinants of health problems such as intimate partner violence.

Through the sociology of diagnosis this exploratory study of intimate partner physical violence diagnosis investigated:

- Classifications, or names, ascribed to incidents of intimate partner violence during emergency department consultations and their classificatory borders.

- Processes through which intimate partner violence became named during emergency department consultations.

- Consequences, in terms of interventions, mobilised during emergency department consultations and the diagnostic classifications they were associated with.

\section{METHODS}

\section{Design and ethical review}

Research design was an applied, descriptive and explanatory, multiple-method approach that involved:

- Qualitative semi-structured interviews with service users and emergency department practitioners to produce rich, descriptive accounts of events and experiences of identification and response to intimate partner physical violence during emergency department consultations. 
- Document analysis of emergency department health records to identify the range and frequencies of classifications of intimate partner violence applied and interventions recorded and to test associations between them.

Favourable ethical opinion was granted by the Social Care Research Ethics Committee and Health Research Authority and site permissions from each participating organisation were obtained.

\section{Participant recruitment}

Three NHS Hospital Trusts and three community-based specialist domestic violence services in the north of England agreed to host this research.

Semi-structured interviews

Participation was on an opt-in basis. Information about the research was communicated to potential participants at staff /service user meetings where possible and/or by distribution of posters. There were three criteria for service user participants: to be female, to have been subject to intimate partner violence, and to have attended an emergency department following intimate partner violence. All emergency department nurses and doctors at the participating NHS Trusts were invited to participate. In total eight women from two services and nine emergency department practitioners from two NHS Trusts came forward to participate. Recruitment was best at organisations that facilitated researcher access to meetings with potential participants.

\section{Emergency department health record document analysis}

Emergency department health record document analysis was only feasible at one NHS Trust that electronically scanned hard copy emergency department attendance records enabling onsite computer-based retrieval and review. Offsite hard-copy record storage and resource intensive retrieval precluded emergency department document analysis at the other two sites. 


\section{Sample}

Because the emergency department clinical coding dataset in England is limited a multistage sample design using data fields most likely to yield an intimate partner violence sample was employed. First, the Electronic Patient Record System was screened at the participating site to produce a sampling frame of all emergency department attendances in 2010 coded with dataset fields i) incident type: 'assault', ii) incident location: 'home/'home other', and iii) age on arrival: sixteen years or older and this identified 491 records. Two separate

months, avoiding periods associated with greater incidence of intimate partner violence (Christmas and international football), were selected and this produced a two-month sample frame of $n=90$ records which were then manually screened for documented partner perpetrated assault. Six records were removed on manual screening because they were not assaults $(n=84)$. Victim-perpetrator relationship was documented in $68 \%(n=57)$ of records, and of these, twenty-eight records (49\%) had documented partner perpetrated assault which produced a sample of 'assault by partner' records $(n=28$; women: $n=24)$. Table 1 provides an overview of the sample and participants.

Table 1 Participants and sample

\begin{tabular}{lc}
\hline Service user interviews & $n=8$ \\
\hline Practitioner interviews & $n=9$ \\
\hline ED records & $n=28$ \\
\hline
\end{tabular}

\section{Data collection}

\section{Semi-structured interviews}

Interviews were undertaken by one female researcher in a private room at a specialist domestic violence service or NHS Trust between December 2011 and May 2012. An interview protocol attended to participants' rights, comfort, safety and well-being. There were no incentives to participate though funding for travel, child care, and interpreter service were available. Participants were aware they could stop the interview and retract participation at 
any time until the final research report was written. Similarly, limits of confidentiality were established should a participant disclose that they or someone else was at risk of harm. Demographic information from interview participants was not deemed necessary for the study and therefore not collected. The interviews lasted between twenty to sixty minutes. Interviews were closed once the topics of the interview guide had been addressed and the participant had nothing further to add. Interviews were audio taped and transcribed by secure transcription service and anonymised (one participant opted-out of interview audiorecording and interview notes were made instead). Alphanumeric codes were applied to individual transcripts: 'SU' signifies service user respondents, EDPN indicates nurse respondents, and EDPD denotes medical practitioner respondents. Numbers following a respondent group code represent i) the district from where the participant was recruited, and ii) a randomly assigned interview number. Anonymised transcripts were checked for accuracy and entered into NVivo9 for data management and analysis.

Emergency department health record document analysis

Qualitative text extracts recorded by ambulance personnel, receptionists, and practitioners to document the incident of intimate partner violence and events of consultation were collected onsite in May and June 2012 and entered into an IBM SPSS ${ }^{\odot}$ data file on a password protected, whole drive encrypted laptop computer.

\section{Data analysis}

\section{Semi-structured interviews}

Semi-structured interviews with service users and practitioners were understood as witness accounts (Hammersley 1992) of emergency department consultations. Following Miles and Huberman's (1994) realist qualitative data analysis, an initial coding framework was developed in NVivo9 nodes for respondents' understandings and experiences of intimate partner violence diagnosis (its category, process of identification, and consequence). Interview data were analysed for respondents' accounts of what constituted 'intimate partner violence' and for explanatory accounts of emergency department consultation events and 
experiences. Thematic categories of data were further analyzed for patterns, recurrences and dissonances, and thematic sub-concepts and connections between them were identified to produce findings that held substantive meaning.

\section{Emergency department health record document analysis}

Classificatory constructs of intimate partner violence and associated interventions were established from data extracted from emergency department health record texts. These constructs underwent quantitative content analysis to identify frequencies of items (vocabulary used and interventions) recorded and to test associations between them. Severity of violence and injuries suffered were scored and quantified with reference to the Conflict Tactics Scale (Strauss 1996) and Home Office crime counting rules (HO 2010) respectively.

Iterative analysis between the different methods was also undertaken. Respondents' qualitative accounts were used to further interpret findings from the emergency department record analysis, and similarly findings from document analysis were applied to further interpret findings from respondents' accounts.

\section{Definitional clarity}

Although the term 'intimate partner violence' better differentiates abuse by a partner from other forms of kin perpetrated violence or violence perpetrated in domestic locations, the term 'domestic violence' to refer to intimate partner violence' remains widespread and both terms are used interchangeably in this paper. Currently, in England, no category of 'intimate partner violence' exists in emergency department administrative health information systems. The multi-stage sample design used in this study was the most feasible method to identify a sample of people attending an emergency department following an incident of intimate partner violence. This design limits the study to include only physical forms of intimate partner violence and labels the sample population in a particular way (assault by partner). 
Reference to this labeling in this paper is not to distinguish assault by partner from intimate partner violence but rather to maintain clarity in relation to the sample population.

\section{RESULTS}

\section{Locations, Actors and Systems}

The emergency department attendance records were complex, constituted by different sources of information collected by different actors for different systems at six different locations of interaction (Figure 1).

Figure 1 Emergency department locations of recorded interaction

\begin{tabular}{|l|c|c|c|c|c|c|}
\hline Ambulance & & $\begin{array}{c}\text { Triage/Nurse } \\
\text { Record }\end{array}$ & & $\begin{array}{c}\text { Safeguarding } \\
\text { Referral }\end{array}$ & \\
\hline 0 & 0 & 0 & 0 & 0 & 0 \\
\hline & Registration & & $\begin{array}{c}\text { Medical } \\
\text { Practitioner }\end{array}$ & & $\begin{array}{c}\text { Diagnosis, } \\
\text { Disposition * } \\
\text { \& GP Letter }\end{array}$ \\
\hline
\end{tabular}

Key: ${ }^{*}$ Disposition refers to the outcome of an emergency department consultation in terms of whether the patient was discharged, referred for follow-up, transferred to another facility or admitted to hospital

Not all records had information recorded at each location. Of the 28 assault by partner records, 16 had been transported by ambulance, all had registration, triage/nurse, and diagnosis/GP letter records, 24 had a medical practitioner record and 6 had a safeguarding record documenting referral of service users' children to social services. Registration and Diagnosis/Disposition form part of the NHS dataset that NHS Trusts are mandated to record for each episode of care and this information was present for all records.

\section{Classifications across locations}

Seven different terms or classifications had been used to record an assault by partner and these were:

- 'assault by partner', 
- 'alleged assault by partner',

- 'assault',

- 'alleged assault',

- 'domestic violence',

- 'acts-based classifications' (e.g. 'strangled' , 'hit', 'head-butted')

- 'injury-based classifications' (e.g. 'nose injury', 'head injury', 'wrist injury')

The range and frequency, in proportional percentages, of different classifications mobilised by different actors at different locations are illustrated in Figure 2.

Figure 2 Range and frequency of classifications used at the different locations *

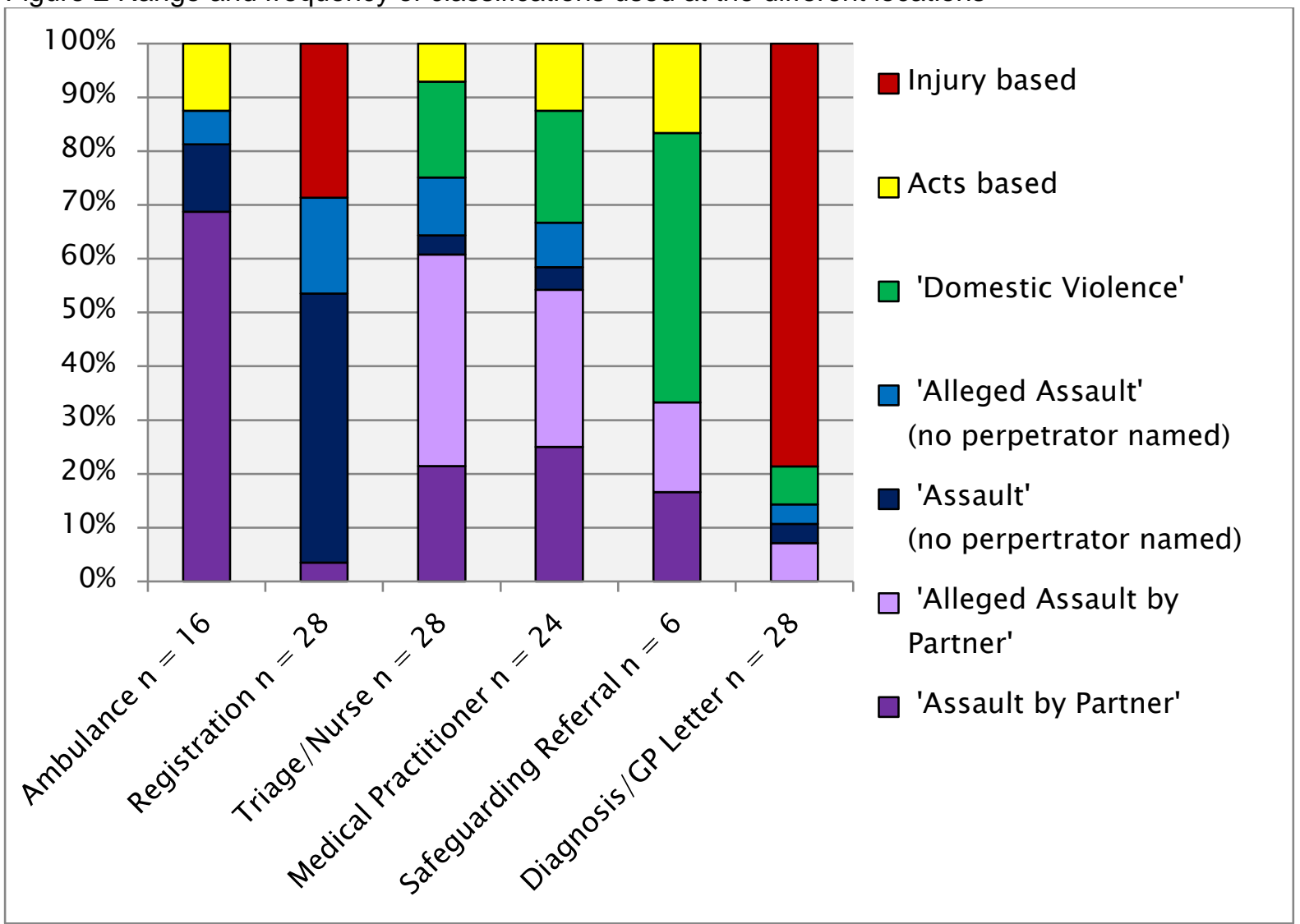

${ }^{*}$ The most specific classification was counted if more than one classification had been used.

The most common classification used in ambulance records was 'assault by partner' $(\mathrm{n}=$ 11/16, 69\%). The term 'Assault' was most frequently entered, in free-text space, at 
registration ( $n=14 / 28,50 \%)$. 'Assault' is one of six options to categorise 'incident type' in the national emergency department dataset, and its free text use by registration staff may reflect this. A victim-perpetrator relationship was documented in the majority of practitioner records across ambulance $(75 \%, n=12)$ triage $(82 \% n=23)$, medical practitioner $(92 \%, n=22)$, and safeguarding referral (100\%) locations. The term 'alleged' pre-fixed 'assault' in a significant minority of triage $(39 \%, n=11 / 28)$ and medical practitioner records $(29 \%, n=7 / 24)$. The classification 'domestic violence' was applied in some triage and medical practitioner records though it was more regularly applied in safeguarding referrals $(50 \%, n=3 / 6)$. At Diagnosis, Disposition, and GP Letters location, the majority of records $(n=22,79 \%)$ solely had injurybased classifications. Classifications recorded by medical practitioners at this location were electronically entered and thus likely constrained by the injury-based NHS dataset options. Recording of violence for GP letter information required practitioners to manually type into a free text space, and this was done on six (21\%) occasions, though just half of these included victim-perpetrator relationship information (11\%). Figure 1 importantly illustrates multiplicity of intimate partner violence classifications applied across people's emergency care pathways and which co-existed in their health records.

\section{Classificatory transformations}

Figure 1 also illustrates a general classificatory transformation from 'assault by partner' to an 'injury-based classification'. This transformation that for the most part erases partner violence at the point of diagnosis, disposition and GP letter was mobilised by administrative dataset field options and practitioners' classifying and recording practices. This finding is important because it means that information about intimate partner violence as the cause of a health problem infrequently extended beyond the emergency care episode to the person's general practitioner from whom long term and follow-up services are accessed. In contrast, service users (SU24, SU28, SU43, and SU49) thought that information about the assault and victim-perpetrator relationship would have been conveyed to their general practitioner, 
indicating an information disconnect that could adversely impact outcomes of the person's follow-up care.

\section{Recording practices}

The term 'alleged' was rarely applied to prefix documentation of intimate partner violence in ambulance records, conversely it was used in half of all triage/nurse and medical practitioner texts ( $n=15,54 \%$ and $n=11,46 \%$ respectively). In one triage text the following was observed: 'BIBA [shorthand for 'brought in by ambulance'] assaulted by partner' recorded in typeface above which in a handwritten postscript the word 'allegedly' had been added (Figure 3).

Figure 3 'allegedly'

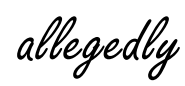

$\mathrm{BIBA}_{\wedge}$ assaulted by partner

Pre-fixing an account of violence with the term 'alleged' was a common practice; six practitioners (EDPN14; EDPD15; EDPN16; EDPN17; EDPD23; and EDPD28) reported recording assaults as 'alleged', exemplified in the following account:

"in terms of the A\&E [Accident and Emergency] card, terminology is important and for someone who's obviously been assaulted you would always write alleged assault because that's what it is, it's alleged assault by the patient. And a lot of the times it's blatantly obvious that it is actual assault."(EDPD28)

Recording 'alleged' then was not intended to represent an alternate interpretation of events as told, nor dispute patients' accounts. This perspective was echoed by other respondents (EDPD15, EDPD23, EDPN14, EDPD29), and as one practitioner explained:

"it's alleged because you haven't witnessed it but you do believe the patient" (EDPD29) 
Non-witnessing of violence was justification for introducing 'alleged' into recording practices. However, it would similarly be unlikely for ambulance personnel to directly witness intimate partner violence in progress, yet the use of alleged by ambulance personnel was exceedingly rare. It is possible that ambulance personnel's attendance at, and thus witnessing, the scene of an assault influenced them to record the more categorical term: assault by partner.

\section{Diagnosis as Category: variations in classificatory borders}

In explicating recording practices one nurse respondent explained:

"I tend to write alleged assault by partner, rather than victim of domestic violence, really. I don't know whether... I suppose there's different connotations to assault and domestic violence... somewhat different connotations, really, but it's the same thing." (EDPN14)

In this extract there is a double manoeuvre, the first distinguishes ("different connotations") 'domestic violence' from 'alleged assault by partner', and the second re-assimilates ('but it's the same thing"). This practitioner went on to say:

“It's [domestic violence] not something that's used in A\&E very much at all. (...) it is more assaults, you know, been assaulted by partner. And I don't know whether that's made it almost more acceptable as just something that happens. And I think domestic violence is more of a... has more serious connotations to it ... if you hear someone's a victim of domestic violence you might be more worried". (EDPN14) In this account different classifications were important as they altered the practitioner's reading of the situation, and on 'different connotations' the respondent further explained:

"I suppose assault, I would think of an alcohol fuelled situation, where someone's lashed out and hit their partner, or been violent towards them. And I suppose domestic violence is a long-term, chronic problem that happens with or without alcohol. It's something that's an ongoing... Whether that's right or wrong, I don't know. But that's just what I would... But I suppose they should both be classed as 
domestic violence, really. The fact that alcohol's involved shouldn't have any bearing on it, really." (EDPN14)

Here a distinction is made between 'assault by partner', boundaried as 'one-off', 'extraordinary' ("lashed-out'), 'alcohol-fuelled' violence between partners, and 'domestic violence' differentiated as ongoing, more serious, and not necessarily linked with alcohol consumption. The idea of normative, 'not domestic violence' partner violence was shared by other respondents:

"the majority of things that I've seen have been, sort of, one off drunken, you know, I've had them go out tonight both the female and the male person drunk, and it's a sort of one off occurrence, at that point in time. (...) they've come together and they're both there (...) And generally the male's there and apologetic and the both of them have been, sort of like, the female's, sort of, been, "Well, I was hitting him at the same time and he's hit me back, ..harder than... Do you know what I mean? Those sort of cases really." (EDPD23)

For this practitioner 'one-off', 'alcohol-related' partner violence was understood to be the type most commonly seen and much higher in their caseload volume than 'domestic violence'. Importantly though, and in contrast, most people in this record sample had been subject to severe (medium and high level [Strauss 1996]) violence $(n=24 / 26,92 \%)$ and suffered significant (medium or high level [HO 2010] injury ( $n=22 / 25,88 \%)$. Low level, minor violence was thus infrequent in this 'assault by partner' sample.

Gendered difference in terms of bodily force ('hitting harder') was also referenced in this practitioner's account and then marginalised as normalised mutual violence was re-centred. From these practitioner accounts, previous violence signaled 'domestic violence' and this was also evident in record documentation: nine records documented whether there had been previous partner violence or not. In records that affirmed previous partner violence $(\mathrm{n}=$ $8 / 9)$, the classification 'domestic violence' was frequently used $(n=5 / 8,63 \%)$. 


\section{Diagnosis as Process: modes of reporting intimate partner violence}

For intimate partner violence the process of diagnosis refers to modes of service user report, whether service user initiated self-report, practitioner initiated report (self-report on being asked), and non-report. Practitioner responses about usual mode of report differed. Three practitioners (EDPD29, EDPN14 and EDPN21) indicated that most service users readily self-reported as illustrated in this account:

"most seem quite happy to disclose it, especially if they come with the police.

Whether it's because they're used to it or it just seems to be that's their life. They don't seem to have any qualms about, they're, like, this is what's happened, (...) l've never had to probe anybody or... It's generally information that's volunteered, really." (EDPN14)

In this account targeted, deeper questioning is signaled by the use of the word 'probe'. The idea of having to probe were elements of a mode of report that when activated mobilised practitioners to classify an assault by partner differently than in situations of overt self-report. For four practitioners (EDPD15, EDPN16, EDPN17, EDPN22), practitioner initiated report was usual and this made practitioner led enquiry necessary for identifying intimate partner violence, as this practitioner explained:

“Normally you've to ask. (...) sometimes they're that controlled that they're not allowed to say anything until they're asked. So they're waiting to be asked". (EDPN22)

This research found two contrasting, yet coexisting discourses about usual modes of report: active service user initiated report and practitioner initiated report.

\section{Practitioner initiated report}

Practitioner initiated report required practitioners to have an index of suspicion that the person may have been subject to intimate partner violence. One nurse described her ability 
to know that something was wrong in the context of service user non-report and this ability to 'just know' was based on professional experience developed over time, explaining:

“it goes back to experience, you just know sometimes that's something's just strange. The majority of people are just as they are, (...) l've fallen and slipped on the ice and it's icy outside, it all adds up. (...) and I do think that maybe we do lose some, some slip through the net, because a junior member of staff or a doctor who's just like yeah, yeah, yeah, because they're not as in tune with it as we are as nurses." (EDPN21)

This account suggests that identification is dependent upon an experienced practitioner able to recognise intimate partner violence and that nurses, because of greater awareness were more likely than junior doctors to recognise it. The idea that intimate partner violence was unintelligible to those lacking experience was further advanced by one of the medical practitioners:

"it relates to picking it up in the first place, which is often difficult. It will be the nurse who intuitively picks it up, a female nurse in a female patient. Invariably these patients are seen by a relatively junior doctor, who won't have the insight or intuition to pick it up, and even if they do it's unlikely they will do a lot about it. It will be the nurse concerned who will initiate referral to domestic violence services." (EDPD28)

Constructed in this way as often obscure and necessarily requiring practitioner initiated identification could inadvertently legitimise non-identification in practice.

\section{Service user initiated report}

Service users identified a number of ways that emergency department practitioners had become informed of their being subject to partner violence: two service user respondents self-reported (SU24, SU49), two said that accompanying police had informed health practitioners (SU28, SU43), and another self-reported after being asked why the police had dropped her off (SU27). 
The connection between involvement of the police and accessing health services following an incident of intimate partner violence was an important one. Indeed, report to police prior to emergency department attendance had been documented in $71 \%(n=20 / 28)$ of the assault by partner health records in this study. Although practitioner respondents (EDPD14, EDPN16; EDPN17, EDPD29, EDPN21) were familiar with prior police involvement, the following account exemplifies that prior service user report to police may operate in a paradoxical way:

"(...) often they come in with the police, the police are already involved. So whether we presume because the police are involved, we don't need to offer any other assistance. That's probably the wrong thing, because I'm not sure what the police can offer, other than arresting the perpetrator." (EDPN14)

In this account practitioner knowledge of police report lessened the need for emergency department intervention even though there was uncertainty about usual police service response.

Further, service user respondents (SU43, SU49, SU27, SU28) also described practitioner non-response and seeming indifference to their self-report of an assault by their partner, as this extract illustrates:

"I remember them saying you've got some nasty things here, and I was telling them that this woman [same-sex partner] had attacked me from behind, beat me up, she stamped on my head and stamped on my body and everything and beat me. And they said 'oh right', but I don't know if they were taking notes or what, but they were generally dealing with my wounds and everything, and they said, "Right, we'll get your arms $x$-rayed (...) and I just went home in a daze." (SU49) For this service user self-report clearly did not trigger identification of, or interventions, for intimate partner violence. 


\section{Diagnosis as Consequence: response and interventions}

Frequencies of intimate partner violence interventions advocated in policy documents (DH 2005, NICE 2014) (accurate documentation of the event; risk assessments; provision of information; and referrals to specialist domestic violence and social services) that were recorded by emergency department practitioners are presented in Table 2.

Table 2 Frequency of items recorded during consultation

\begin{tabular}{l|l|l} 
Items & $\%$ & $\mathbf{N}^{*}$ \\
\hline Record of violent acts & $88 \%$ & $n=21 / 24$ \\
Record of relationship to perpetrator & $92 \%$ & $n=22 / 24$ \\
Record of previous partner violence & $32 \%$ & $n=9 / 28$ \\
Record of whether first episode & $<1 \%$ & $n=1 / 24$ \\
Record of frequency of violence & $8 \%$ & $n=2 / 24$ \\
Record of injuries & $100 \%$ & $n=24 / 24$ \\
Body map record of injuries & $54 \%$ & $n=13 / 24$ \\
Photographic recording (or offer of) of injuries & $4 \%$ & $n=1 / 24$ \\
Record of risk to person & $4 \%$ & $n=1 / 24$ \\
Record of children in household or pregnancy & $36 \%$ & $n=10 / 28$ \\
Record of information provided & $0 \%$ & $n=0 / 24$ \\
Record of referral (or known) to specialist violence services & $4 \%$ & $n=1 / 24$ \\
Record of referral to children's services & $25 \%$ & $n=7 / 28$ \\
\hline
\end{tabular}

${ }^{*}$ Ns vary because some response information (previous partner violence, risk to children/foetus and referral to children's social services) was recorded at triage/nurse locations $(n=28)$ rather than in the medical practitioner records $(n=24)$.

Violent act(s) (88\%), perpetrator relationship (92\%), and physical injury suffered (100\%) were items most frequently recorded. Although context of violence was important in practitioners' accounts of what constituted 'intimate partner violence' this was infrequently documented, in terms of whether the violence was ongoing or not (32\%), a first episode (5\%) or its frequency (8\%). In relation to accurate recording, body maps of injuries were completed for just over half, and the offer of photographic recording was documented once.

Interventions too were infrequently documented. The most commonly recorded risk assessment was risk to children (36\%); risk of serious harm for the adult victim-survivor was identified and recorded once. Referral to children's services (25\%) was the most commonly 
recorded intervention. Provision of information about or referral to, specialist services was not documented on any record. A woman's ongoing engagement with specialist services was recorded once. From this document analysis 'risk' was the principal rubric that mobilised intervention.

\section{Rubric of risk-based intervention}

'Risk' for the adult victim-survivor was expressed in terms relating to the definition in UK law of 'serious harm' (GMC 2009), as this practitioner articulated:

"if they've made the decision they don't want to disclose it and it doesn't seem that anyone else is at risk, you then need to make a certain amount of judgment of, say how much risk they're at. If it's someone who's generally been beaten black and blue, or stabbed, or there's major injuries, you might have to rethink it. If it's someone who has been slapped or pushed into a wall, or something like that, I certainly wouldn't say it's acceptable, but it's something where you don't think their life is particularly at risk." (EDPD15)

Interventions under the rubric of risk for the adult service user were discussed by four practitioners (EDPD15, EDPD28, EDPD23, EDPN14) to justify referral to police or social services, with or without consent, because of a person's risk of serious harm.

Similarly, risk of harm governed interventions for any children of adults attending an emergency department following partner violence. In this study, ten emergency department attendance records (36\%) had information documented about whether the person had children or was pregnant, and in six of these records (60\%) the term 'domestic violence' had been applied. Though it did not reach statistical significance, 'presence of children or pregnancy' was an important dimension for classifying an event as 'domestic violence $(p=0.0514$, Fisher's exact test). Interconnections between systems to safeguard children and the classification of 'domestic violence' were also articulated by practitioners: 
"If there's a risk to underage children, that certainly changes the equation quite a bit. And I think my threshold for flagging concerns if there were children present or at home, would certainly be lower than it would be for an adult, if they were the only person involved with it." (EDPD15)

Different legal thresholds of risk in UK law (UK Parliament 2002) means that children of an adult victim-survivor may mobilise identification and intervention yet the adult victim-survivor may not, and this is an important paradox of identification consequences found at this interface between health, legal and social care systems.

\section{Specialist services intervention}

Accounts from service user respondents in this study were clear that intimate partner violence specific interventions such as provision of information, referral to specialist services and perpetrator distancing were not forthcoming during their consultations. On being asked about interventions, service users reported:

"Nobody offered me any help or assistance at all." (SU43)

"They looked after me and they would, you know, make sure I was alright. But it's like some of them didn't help, you know, finding somewhere to go. I had to go back to him. They didn't help me in that kind of way, only because it had been going on for a while then they started helping me." (SU28)

"They asked if l'd be alright being able to go home on my own (...) I didn't really feel that the emergency department really helped. They didn't offer any other services afterwards, like [local domestic violence service] - I had to find them out myself." (SU27)

Though practitioners in this study reported providing information about and referral to specialist services, these service user accounts indicate this was not routinely so. Furthermore, the data from attendance records (Table 2) illustrates clearly that non-statutory interventions for intimate partner violence were not formalised or routine components of documentation. 


\section{DISCUSSION}

\section{Sociology of intimate partner violence diagnosis}

Through the sociology of diagnosis, this study finds that that classification of an assault by partner as 'intimate partner violence' was contingent, and more or less likely in relation to items associated with its classificatory category, processes, and consequences (Table 3).

Table 3 Item effect on 'intimate partner/domestic violence' classification in ED consultations

\begin{tabular}{|l|c|}
\hline CATEGORY & Classification \\
\hline Repeated acts of violence & $\uparrow$ \\
\hline On-off act & $\downarrow$ \\
\hline Severe violence & $\uparrow-$ \\
\hline Alcohol consumption & $\downarrow$ \\
\hline Gendered relations & $\uparrow-$ \\
\hline Police involvement & $\downarrow-$ \\
\hline Presence of children & $\uparrow$ \\
\hline PROCESS & $\downarrow$ \\
\hline Self-report & $\uparrow$ \\
\hline Non or reluctance to report & \\
\hline CONSEQUENCE & $\uparrow$ \\
\hline Risk of serious (life-threat) harm & $\uparrow$ \\
\hline Risk to children &
\end{tabular}

Key: $\uparrow$ Classification more likely

$\downarrow$ Classification less likely

- or no apparent effect

Discrete versions of 'intimate partner violence' were constructed in emergency department consultations. The findings evidence different classificatory thresholds and borders between 'intimate partner, or domestic violence' and 'assault by partner' and which could explain variations in health service experiences and outcomes found in previous research.

\section{Classificatory thresholds}

The most common classificatory version found was 'assault by partner'. 'Assault by partner' was defined through conceptions of 'low-level', 'one-off' and/or alcohol fuelled violence. Low level, normalised couple violence as defined by Straus (1996) includes minor acts (push, grab, shove, slap) unlikely to cause physical injury. However, in this context of emergency 
department consultations, most had been subject to severe levels of violence and sustained significant injury. Further, classifying an assault as 'one-off' in this context is problematic because emergency departments do not usually continue relationships with service users beyond an episode of care and emergency department administration systems are not configured to routinely connect present day reports of intimate partner violence with past or future episodes of care. Whilst some partner violence may be 'one-off', practitioners cannot know this. In addition, a 'one-off' or first episode of violence, whether associated with alcohol or not, introduces potentiality and threat of future violence. Made distinct from these 'assault by partner' cases was 'intimate partner or domestic violence'. Previous partner violence held classificatory association for 'intimate partner violence'. 'Intimate partner violence' was considered more serious and of lower caseload volume by practitioners in this study.

\section{Classificatory processes}

Women in this study were instrumental in accessing services and reporting an assault by a partner, yet this method of self-report did not fit with some practitioners' conceptualisation of 'intimate partner violence' being done. Practitioners often thought of 'intimate partner violence' as difficult to identify. So whilst active report to emergency services resulted in immediate access to medical care, there was not necessarily a corresponding mobilisation of classification and intervention by emergency department practitioners. This inversion of active self-report and (not)classifying signals power relations in consultations: bringing 'intimate partner violence' into being in emergency department consultations did not rest with a person's self-report of it. The self-reporting adult with capacity and with continued investment in the intimate relationship was read as a lack of desire for intervention. Paradoxically, reluctance to report was not interpreted as a person's desire for nonintervention and was effective for mobilising classification and intervention. Surely the converse should be true, that self-report routinely mobilises identification and intervention in the emergency department consultation. That women actively self-report is presently not dealt with in current policy documents and there are assumptions that women need to be 
asked. Whilst this may be so for some women, this finding, of women's active self-report, is important for the wider academic and practice community working in this field because it extends the dimensions of usual modes of report of intimate partner violence.

\section{Classificatory consequences}

For the population whose partner assault did not reach the classificatory threshold of 'intimate partner violence', interventions did not extend beyond routine medical care. However, connected to the classification 'intimate partner, or domestic, violence' were specialist interventions and assessments of risk of serious harm for the adult service user. 'Serious Harm' mobilised a formalised legal system of intervention that involved notifying the police and other agencies of the risk. Applications of 'Serious Harm' were rare. The classification 'domestic violence' was more frequently applied in association with the presence of children in the service user's household than for the adult attending the emergency department. This diagnostic paradox likely results from the lower threshold for intervention for children than adults in English law (UK Parliament 2002) which requires practitioners to refer children to social services for the potential risk of harm from witnessing domestic violence or being in a household where domestic violence had taken place.

Whilst statutory-bound interventions were formalised in practice, importantly, the recording of specialist violence intervention was not routine. This may change as emergency departments in England increasingly employ Independent Domestic Violence Advocate (IDVA) (Basu and Ratcliffe 2014, Coy and Kelly 2011) and specialist domestic abuse nurse (McGarry and Nairn 2015) services onsite. Nonetheless, identification by practitioners is crucial for referral to these services. Importantly this research suggests that even in departments where specialist services are embedded, it is likely that the unrecognised 'assault by partner' intimate partner violence population will not receive referral to them. 


\section{Recording practices}

Health records first and foremost document patient health care contacts. The British Medical Association (BMA) provides guidance on record-keeping stating that: "Health records must be clear, accurate, factual, legible and should be contemporaneous. They must include all relevant clinical findings, the decisions made, information given to patients, and drugs or treatment prescribed. Personal views about the patient's behaviour or temperament should not be included unless they have a potential bearing on treatment' (BMA 2014:2). Though there is a good amount of literature about medical documentation of sexual assault (Walby et al 2015), there is much less for physical assault. In England, professional guidance for the recognition and management of domestic violence (RCEM 2010) states that: "The patient should be believed" (RCEM 2010:2) but does not offer guidance on documentation. However US guidance advises practitioners to: "Avoid such phrases as "patient claims" or "patient alleges," which imply doubt about the patient's reliability" (Isaac and Enos 2001:3-4). Documenting a reported assault as 'alleged' was a minority, but nonetheless common practice found in this study. Application of 'alleged', defined as 'represented as existing or as being as described but not so proved; supposed" (Farlex 2015) imbues uncertainty about events and yet validating a person's experience of intimate partner violence is a cornerstone of first response (DH 2005). Under the Data Protection Act (UK Parliament 1998) patients in England have the right to request that factual inaccuracies in their health record be rectified or deleted (MPS 2015) and therefore could ask that references to events being 'alleged' be removed from their record.

Health records also have secondary uses (MPS 2015) and in the context of intimate partner violence, i.e, a criminal act, medical practitioners may be asked to provide an expert report for courts of law. In producing an expert report UK practitioners must follow Civil, Criminal, or Family Procedure Rules and their respective Practice Directions (MoJ 2013; BMA 2015), the fundamental duty of which is to 'help the court on maters within their expertise'. A medical expert report provides an opinion based on 'reasonable medical certainty' or 'reasonable 
medical probability' for questions asked by the court (de Souza and Wise 2015). The law also recognises that there will be some element of uncertainty in medical expert reports and collectively this means, in the context of an assault, that medical practitioners provide an expert opinion on whether the event described (act(s) of violence) more likely than not was the cause of the injury described (de Souza and Wild 2015). Importantly then, medical expert reports are not about providing an opinion as to whether an assault took place or not. Furthermore, in addition to providing information about the material elements of the consultation, the law permits medical practitioners to provide information of patients' accounts of events recorded at the time of the consultation (de Souza and Wise 2015). Thus, there is no legal or professional requirement for practitioners to record a reported assault as alleged, nor to document a report of violence by a partner as an assault if this is not how the person described it.

\section{Administrative data collection}

This research identified systematic difficulties in undertaking intimate partner violence research in NHS Hospital Trusts in England. The present NHS dataset entered at the point of service access, means that anonymous, system level intimate partner violence audit or research is not possible. Lack of routinely collected information about intimate partner violence in administrative health information systems is a wider, global issue (EIGE 2014, WHO 2103b). Administrative data collection is important so that identification, health impact and responses can be quantified at systems levels to improve public health knowledge about the health burden of intimate partner violence and inform evaluations of violence prevention strategies. To enable anonymous system level monitoring of intimate partner violence, administrative data sets would need to include field options for victim-perpetrator relationship and for non-health service follow-up such as 'specialist violence services' and 'social services' and which would help to formalise and more widely embed specialist intervention systems in practice. It is also possible that follow-up and continuing care (specialist violence, 
injury, mental health and community) services may be improved if information about the violence, location, and victim-perpetrator relation was included in diagnosis and GP letter.

\section{Classificatory multiplicity}

This study has found classificatory multiplicity during emergency department consultations following intimate partner violence. Different labels were applied by different practitioners at different times and places which, through complexity theory, signal dynamic intersections of medico-socio-legal systems in operation. It is likely that these intersecting systems more keenly surface in emergency care contexts where people seek care for injuries sustained through violence. Differently valorised versions of intimate partner violence were brought into being through a disciplinary gaze (Foucault, 2003 [1963]) of risk informed practices. In this power-knowledge nexus 'each category valorizes some point of view and silences another' (Bowker and Star 1999:5).

Valorisation of different systems at different points in emergency department pathways likely explains this classificatory multiplicity. At the start the 'assault by partner' is foregrounded as the cause of injury warranting medical attention. As assessment of extent of injury and clinical management takes priority the 'assault' is backgrounded, surfacing again in relation to risk of serious harm to the adult service user and potential risk of significant harm (domestic violence) for any children, and then largely disappearing through injury framed diagnoses. Comprehended in this way as functional and transitional, classifications were fluid yet dynamically connected through diagnostic categories, processes and consequences of particular labels. Explaining how phenomena enter our social reality, Woolgar and Lezuan propose:

"objects are brought into being, they are realized in the course of a certain practical activity, and when that happens, they crystallize, provisionally, a particular reality, they invoke the temporary action of a set of circumstances." (2013:323-4). 
Through this frame of classificatory multiplicity and provisionality different versions of intimate partner violence emerged. These different versions also signal enactments of different practices and service pathways that likely make a difference to service user experiences and outcomes of emergency department consultations following intimate partner violence.

This research found that when an 'assault by partner' was connected to 'intimate partner violence' it was most often through the rubric of risk assessment practices bound to the state (acts of parliament) and medico-socio-legal systems (interpretations of risk of serious harm [adult] and significant harm [child]) explaining why some intimate partner violence, that did not reach these classificatory thresholds, may be missed. Furthermore identification of intimate partner violence may also be disrupted by recording practices (prefixing with 'alleged',) and administrative dataset data field options ('assault' and 'injury').

\section{Limitations}

This research is constrained by its sample size and number of participants. Nonetheless, this conceptual, 'fuzzy', slice (Paley and Eva 2011) of data likely signals macro and micro sociocultural systems shaping intimate partner violence diagnosis in emergency department consultations. Whilst it is implausible to consider that complete account of phenomena is possible, following Capra (1996) the claims of this research are for credible, greater approximations of knowledge about intimate partner violence diagnosis in emergency departments in England.

\section{CONCLUSION}

This research found that different versions of intimate partner violence were constructed during emergency department consultations. By explicating these different versions through their diagnostic categories, processes, and consequences, interconnected structures of state, society, medical and legal systems were seen to shape intimate partner violence 
diagnosis and which can explain why some women still report that intimate partner violence was not identified and/or responded to during their emergency department consultation. This study found that self-reported partner violence and incidents classified as 'low level, 'one-off' or 'alcohol fuelled' were less likely to be named as 'intimate partner violence'. The classificatory threshold for 'intimate partner violence' was found to be based on practitionerinitiated report, previous partner violence, severe violence, serious harm and/or fear. This threshold is too high: fear may not be evoked by a first episode or early experiences of partner-perpetrated violence, firstly because a pattern of physical violence has not been established, and secondly, because the severity of partner violence, when allowed to continue, commonly escalates over time (Kimmel 2002). It is clear that strengthening systems of diagnosis (identification and intervention) by lowering the classificatory threshold so that all incidents of partner violence are named as 'intimate partner violence' will reduce the incidence of missed intimate partner violence and afford earlier specialist intervention to reduce violence and limit its harms. Lowering the classificatory threshold for intimate partner violence in this way will contribute to improved health experiences and consultation outcomes for this population.

The findings also indicate a need for best practice professional guidance to advise practitioners on recording service user reports of interpersonal violence, injuries sustained, information provided, decisions made and interventions mobilised and from which locally relevant standards for documentation could be developed. There is also a need for NHS administrative data sets to be upgraded to include field options for victim-perpetrator relationship and for non-health service follow-up such as 'specialist violence services' and 'social services'. This would help formalise specialist intervention systems in practice and permit anonymous system level quality monitoring of identification and response to intimate partner violence. 


\section{RELEVANCE TO CLINICAL PRACTICE}

This research provides an account of the complexities of intimate partner violence diagnosis during emergency department consultations. The findings illustrate that identification of and response to intimate partner violence, even in contexts of severe physical violence, was not straightforward and was contingent. This comprehension of identification and response as contingent on classificatory thresholds relating to intimate partner violence diagnostic categories, processes, and consequences offers an explanatory account of why intimate partner violence may continue to be missed in emergency department consultations. The current threshold for identification is too high. Practitioners could make a significant contribution to reducing the number of missed cases of intimate partner violence during emergency department consultations if the classificatory threshold was lowered so that all reported incidents of partner violence were identified as 'intimate partner violence'. Responding to all service user reports of partner violence with specialist intimate partner violence intervention in line with local policy, service availability and legal requirements affords earlier specialist interventions to reduce violence and limit its harms, and which will improve health experiences and consultation outcomes for this population. This research has relevance for practitioners and managers working in first contact health services (ambulance, urgent and emergency care, general practice) or any setting where service user report of intimate partner violence is possible. 


\section{REFERENCES}

Basu S \& Ratcliffe G Developing a multidisciplinary approach within the ED towards domestic violence presentations. Emergency Medicine Journal 31, 192-195 doi:10.1136/emermed-2012-201947.

Beynon CE Gutmanis IA Tutty LM Wathen CN MacMillan HL (2012) Why physicians and nurses ask (or don't) about partner violence: a qualitative analysis. BMC Public Health 12 , 473.

Black MC Basile KC Breiding M J Smith SG Walters ML Merrick MT Chen J \& Stevens MR (2011) The National Intimate Partner and Sexual Violence Survey (NISVS): 2010 Summary Report. National Center for Injury Prevention and Control, Centers for Disease Control and Prevention, Atlanta, Georgia.

Boursnell M Prosser S (2010) Increasing identification of domestic violence in emergency departments: A collaborative contribution to increasing the quality of practice of emergency nurses. Contemporary Nurse: A Journal for the Australian Nursing Profession 35 (1) 35 - 46.

Bowker GC \& Star SL (1999) Sorting Things Out: Classification and its Consequences. The MIT Press, London.

British Columbia Centre of Excellence for Women's Health (BCCEWH) (2013) Review of Interventions to Identify, Prevent, Reduce and Respond to Domestic Violence. NICE, London. Available at: https://www.nice.org.uk/guidance/ph50/resources/review-ofinterventions-to-identify-prevent-reduce-and-respond-to-domestic-violence2 (accessed 30th November 2015).

British Medical Association (BMA) (2014) Access to health records: Guidance for health professional in the United Kingdom. BMA, London. Available at: http://bma.org.uk/support-atwork/ethics/confidentiality-and-health-records (accessed 30th November 2015).

British Medical Association (BMA) (2015) Being an expert witness.BMA, London. Available at: http://bma.org.uk/developing-your-career/portfolio-career/being-an-expert-witness/whatis-involved (accessed 30th November 2015)

Brown P (1995) Naming and Framing: The Social Construction of Diagnosis and Illness. Journal of Health and Social Behaviour 35, Extra Issue, 34 - 52.

Capra F (1996) The Web of Life: A New Scientific Understanding of Living Systems. Anchor Books, New York.

Catallo C Jack SM Ciliska D \& MacMillan HL (2013) Minimizing the risk of intrusion: a grounded theory of intimate partner violence disclosure in emergency departments. Journal of Advanced Nursing 69 (6) 1366 - 76.

Choo EK Nicolaidis C Newgard CD Lowe RA Hall MK \& McConnell KJ (2012) The Association between Emergency Department Resources and Diagnosis of Intimate Partner Violence. European Journal of Emergency Medicine 19 (2) 83 - 88.

Cilliers P (1998) Complexity Theory and Postmodernism: understanding complex systems. Routledge, Oxon.

Coben JH (2002) Measuring the quality of hospital-based domestic violence programs. Academic Emergency Medicine 9 (11) 1176 - 1183. 
Coy M \& Kelly L (2011) Islands in the Stream: An evaluation of four London independent domestic violence advocacy schemes. Child and Woman Abuse Studies Unit, London Metropolitan University, London.

Department of Health (2005) Responding to domestic abuse: a handbook for health professionals. Available at:

http://www.domesticviolencelondon.nhs.uk/uploads/downloads/DH 4126619.pdf (accessed 30th November 2015).

de Souza B \& Wise J (2015) I'll see you in court: working as an expert witness. Available at: http://careers.bmi.com/careers/advice/l\%E2\%80\%99ll see you in court\%3A working as an expert witness (accessed 30th November 2015).

European Institute for Gender Equality (EIGE) (2014) Administrative Data Sources on Gender-Based Violence Against Women in the EU: Current Status and Potential for the Collection of Comparable Data. Available at http://eige.europa.eu/sites/default/files/MH0113492ENN PDF.Web .pdf (accessed 30th November 2015).

Farlex (2015) Free Dictionary Online. Available at: http://www.thefreedictionary.com/ (accessed 30th November 2015).

Feder G Ramsay J Dunne D Rose M Arsene C Norman R Kuntze S Spencer A Bacchus L Hague G Warburton A \& Taket A (2009) How far does screening women for domestic (partner) violence in different health-care settings meet criteria for a screening programme? Systematic reviews of nine UK National Screening Committee criteria. Health Technology Assessment 13(16) Available at:

http://www.journalslibrary.nihr.ac.uk/ data/assets/pdf file/0011/64694/FullReporthta13160.pdf (accessed 30th November 2015).

Foucault M (2003) [1963] The Birth of the Clinic. Routledge Classics, London.

General Medical Council (GMC) (2009) Confidentiality. GMC, London. Available at: http://www.gmc-uk.org/guidance/ethical guidance/confidentiality.asp (accessed 30th November 2015).

Hammersley M (1992) What's Wrong with Ethnography? Routledge, Oxon.

Hathaway JE Willis J Zimmer B (2002) Listening to survivors' voices: addressing partner abuse in the health care setting. Violence Against Women 8 (6) 87-719.

Home Office (2010) Counting Rules for Recorded Crime. Home Office, London. http://webarchive.nationalarchives.gov.uk/20110218135832/http:/rds.homeoffice.gov.uk/rds/ countrules.html (accessed 30th November 2015).

Howard L Trevillion K Khalifeh H Woodall A Agnew-Davies R \& Feder G (2010) Domestic violence and severe psychiatric disorders: prevalence and interventions. Psychological Medicine 40 (6) 881-893.

Hurley KF Brown-Maher T Campbell SG Wallace T Venugopal R \& Baggs D (2005) Emergency department patients' opinions of screening for intimate partner violence among women. Emergency Medicine Journal 22 (2) 97 -98. 
Isaac NE \& Enos VP (2001) Documenting Domestic Violence: How Health Care Providers Can Help. National Institute of Justice, Washington.

https://www.ncjrs.gov/pdffiles1/nij/188564.pdf (accessed 30th November 2015).

Jutel AG (2011) Putting a name to it: Diagnosis in Contemporary Society. John Hopkins University Press, Baltimore.

Kimmel MS (2002) 'Gender Symmetry’ in Domestic Violence: A Substantive and Methodological Research Review. Violence Against Women 8 (11) 1332 - 1363.

Krug EG Dahlberg LL Mercy JA Zwi AB Lozano R (eds) (2002) World Report on Violence and Health. World Health Organisation, Geneva.

McGarry J \& Nairn S (2015) An exploration of the perceptions of emergency department nursing staff towards the role of a domestic abuse nurse specialist: a qualitative study. International Emergency Nursing 23, 65-70.

Miles MB \& Huberman AM (1994) Qualitative Data Analysis. Sage, California.

Medical Protection Society (MPS) (2015) An essential guide to medical records. Available at: http://www.medicalprotection.org/uk/resources/factsheets/england/england-factsheets/ukeng-medical-records (accessed 30th November 2015).

Ministry of Justice (2013) Civil, Criminal and Family procedure rules and their related practice directions. Available at: https://www.justice.gov.uk/courts/procedure-rules (accessed 30th November 2015).

Muelleman RL \& Feighny KM (1999) Effects of an Emergency Department-Based Advocacy Program for Battered Women on Community Resource Utilisation. Annals of Emergency Medicine 33 (1) 62-66.

National Institute for Health and Care Excellence (NICE) (2014) Domestic violence and abuse: how health services, social care and the organisations they work with can respond effectively. NICE, London and Manchester. Available at:

http://www.Igcplus.com/Journals/2014/02/25/r/c/z/NICE-domestic-report.pdf (accessed 30th November 2015).

Olive P (2007) Care for emergency department patients who have experienced domestic violence: a review of the evidence base. Journal of Clinical Nursing 16 (9) 1736-48.

Paley J Eva G (2011) Complexity theory as an approach to explanation in healthcare: A critical discussion. International Journal of Nursing Studies 48 (2) 269 - 279.

Ritchie J Spencer L \& O'Connor W (2003) Chapter 9 Carrying out Qualitative Analysis. In Qualitative Research Practice: A Guide for Social Science Students and Researchers (Ritchie J \& Lewis J eds). Sage, London.

Robinson R (2010) Myths and stereotypes: how registered nurses screen for intimate partner violence. Journal of Emergency Nursing 36 (6) 572- 576.

Royal College of Emergency Medicine (RCEM) (2010) Domestic Violence: Recognition and Management in Emergency Departments. RCEM, London. Available at:

http://www.rcem.ac.uk/Shop-Floor/Clinical\%20Guidelines/College\%20Guidelines/ (accessed 30th November 2015). 
Royal College of Emergency Medicine (RCEM) (2012) Providing a witness statement for the police. RCEM, London. Available at: http://www.rcem.ac.uk/Shop-

Floor/Clinical\%20Guidelines/College\%20Guidelines/ (accessed 30th November 2015).

Straus M (1996) The Revised Conflict Tactics Scale. Journal of Family Issues 17 (3) 283 316.

Taft A O'Doherty L Hegarty K Ramsay J Davidson L \& Feder G (2013) Screening women for intimate partner violence in healthcare settings. Cochrane Database of Systematic Reviews. Available at: http://onlinelibrary.wiley.com/doi/10.1002/14651858.CD007007.pub2/pdf (accessed 30th November 2015).

UK Parliament (1998) The Data Protection Act. Available at:

http://www.legislation.gov.uk/ukpga/1998/29/contents (accessed 30th November 2015).

UK Parliament (2002) Adoption and Children Act 2002. Available at:

http://www.legislation.gov.uk/ukpga/2002/38/contents (accessed 30th November 2015).

UK Parliament (2006) The NHS Act. Available at:

http://www.legislation.gov.uk/ukpga/2006/41/contents (accessed 30th November 2015).

Walby S (2003) Complexity Theory, Globalisation and Diversity: Paper presented to conference of the British Sociological Association. York: University of York, http://www.leeds.ac.uk/sociology/people/swdocs/Complexity\%20Theory\%20realism\%20and \%20path\%20dependency.pdf (accessed 30th November 2015).

Walby S \& Allen J (2004) Domestic violence, sexual assault and stalking: Findings from the British Crime Survey. Home Office Research, Development and Statistics Directorate, London. Available at: http://www.avaproject.org.uk/media/28384/hors276.pdf (accessed 30th November 2015).

Walby S Olive P Towers J Francis B Strid S Krizsán A Lombardo E May-Chahal M Franzway S Sugarman D Agarwal B \& Armstrong, J. (2015) Stopping Rape: Towards a comprehensive policy. Policy Press, Bristol.

Women's National Commission (2010) A Bitter Pill To Swallow: Report from WNC Focus Groups to inform the Department of Health Taskforce on the Health Aspects of Violence Against Women and Girl. Women's National Commission, London.

Woolgar S \& Lezuan J (2013) The wrong bin bag: A turn to ontology in science and technology studies? Social Studies of Science 43 (3) 321 - 340.

World Health Organization (2013a) Global and Regional Estimates of Violence Against Women: Prevalence and Health Effects of Intimate Partner Violence and Non-Partner Sexual Violence. World Health Organisation, Geneva. Available at:

http://www.who.int/reproductivehealth/publications/violence/9789241564625/en/ (accessed 30th November 2015)

World Health Organization (2013b) Responding to Intimate Partner Violence and Sexual Violence Against Women: WHO Clinical and Policy Guidelines. World Health Organisation, Geneva. Available at:

http://www.who.int/reproductivehealth/publications/violence/9789241548595/en/ (accessed 30th November 2015). 
WORD COUNT

7481 (excluding abstract, references, tables, and figures) 